\title{
Urban form Analysis Based on Smart Growth Characteristics at Neighborhoods of 9th District in Mashhad Municipality
}

\author{
Rezvani Kakhki Saeid ${ }^{1}$, Rahnama Mohammad Rahim² \& Mohammad Ajza Shokouhi ${ }^{3}$ \\ ${ }^{1}$ Ferdowsi University of Mashhad, PhD student of International Branch, Department of Urban Planning, Iran \\ ${ }^{2}$ Ferdowsi University of Mashhad, Full professor of geography and Urban Planning, Iran \\ ${ }^{3}$ Associate professor of Geography, Ferdowsi University of Mashhad, Mashhad, Iran \\ Correspondence: Rezvani Kakhki Saeid, Ferdowsi University of Mashhad, Iran, Mashhad, Azadi Square, \\ Ferdowsi University, International Branch. Tel: 989-1544-26731. E-mail: rezvanibox1@gmail.com, \\ rahnamarahim@gmail.com, shokouhim@um.ac.ir
}

Received: February 3, 2018

doi:10.5539/mas.v12n3p141
Accepted: February 13, $2018 \quad$ Online Published: February 28, 2018

URL: https://doi.org/10.5539/mas.v12n3p141

\begin{abstract}
The purpose of this article is investigating the form of cities based on the new approach of urban smart growth and transect. Currently, the smart urban growth by using the transect method has been able to apply the environmental criteria and keep away from sprawl. The design is based on applying transect method in scale of neighborhoods within metropolis zone. In the zones of transect, different indexes of urban forms have defined clearly; furthermore are measurable and analyzable. The second purpose is determining degree of compatibility between urban characteristics within metropolis zone in one hand, and form-base codes of smart growth in the other hand. The case study of present research is selected due to having diversity of urban forms, different kinds of density, land-use and urban natural landscapes. For this diversity, 9th district in Mashhad metropolis was selected. The transect method has six separate zoning from T1 as the most natural and rural indexes, to T6 including most urban and dense indexes. The new method of Space Matrix for measuring the urban is used for transect zoning. By selecting a north- south crosscut in the considered district and exploiting the urban indexes, the Transect typology of each selected urban unit was determined by spacematrix method. Then, resulted indexes for each urban unit separately were assessed by multi-criteria decision-making matrixes(MCDM). Finaly by the hypothesis test part, with respect to compliance of more than $50 \%$ of 26 indexes of urban units of 9th district, it seems that direction of new urban regulation and models totally express avoiding sprawl and tending to ecologic approaches in the concepts of smart growth and urban form characteristics can analyzed.
\end{abstract}

Keywords: form base codes, smart growth, space matrix, transect, urban form

\section{Introduction}

\subsection{Introduce the Problem}

Since late nineteenth and early twentieth century, a set of views and approaches were suggested in the field of urban construction and development in Europe; that consequently the planning knowledge was arouse.

Patrick Geddes and Lewis Mumford by using the principles of biology and ecology suggested the organism theory in the urban development. Based on their viewpoint, the comprehensive plans pattern was introduced. It found legal and official aspect in England and America. Geddes' views jointed with modern urban planning functionalism and were used throughout the world as a comprehensive urban development plan. In fact, Geddes views and the principles of comprehensive plans were dominate on the scientific worldwide thinking for more than half a century; and remained in its origins until the 1960s. However, the effects of this planning method have remained in the Third World countries, including Iran (Mahdizadeh, 1382).

Since the 1960s, designers have found that the conventional zoning (Euclidean method) that dominated urban development over the twentieth century has had a negative impact on the Urban form and suburbs.

\subsection{History of Smart Growth}

In 1982, the design of the Florida Coastal Area made by Duani and Zybrek was one of the first attempts to propose a form-based approach to create liveliness settlements. In 1993, the New urbanism Congress supported 
the form-based regulation.

Andrés Duany and Elizabeth Plater Zyberk, as designers of the movement of new urbanism criticize the comprehensive plans and zoning (Euclidean) land use-base, because those urban regulations had no any physical point of view. They have neither any imagination, diagram and model for recommending nor any imagination about their considered place or even the desired buildings (Geller, 2010).

\subsection{State Hypotheses and Their Correspondence to Research Design}

In this paper, a new approach (Transect method) is used to analyze the urban form. Andreas Duany in Transect Planning said that the transect is an urban planning approach based on ecological principles, but it is also an important analytical tool. He said Transect methodology involves taking a linear cut across a landscape, usually horizontal, along which a diversity of systems and habitats is sampled, measured and analyzed.

The segmentation of the transect continuum is accomplished by dividing it into six different ecozones. The term ecozone is used to promote the link to natural ecologies. Rural elements should be located in rural locations and urban element should be located in more urban locations. In this part of the research, by using the method of documentary and library studies, the urban smart growth and Transect zoning indexes are obtained.

The first purpose of the research is finding the adaptability of Transect method in urban neighborhoods of Mashhad, by using space matrix diagrams and locating ecozones. The final purpose of the research is to determine and measure the compatibility of smart growth indexes in detailed plans and recent urban development patterns in 9th district of Mashhad metropolise. Space matrix diagrams method is a spatial analysis tool for measuring density and other physical factors of urban forms. The space matrix defines density as a multi-variable concept to relate density and urban form. The most important function of the space matrix method, other than presenting a clear definition of density, is to show that the density can be connected with urban form and other urban functions (Berghauser pont \& Haupt, 2009). In this part of the research, the characteristics of a number of blocks and urban areas in 9th district of Mashhad Municipality were collected. It was carried out by the latest development model and detailed plan of the southwestern part of Mashhad, including 9th and 11th districts.

This collection was marked in a north- southern crosscut that is started from the axis of Mashhad subway (Vakilabad Boulevard) and is ended at the natural landscapes of the southern highlands of Mashhad (Khorshid Park). It is expected that most of six ecozones be observed in the above cross-section. Then, the specifications of above blocks and areas are compared and tested by the graphs of math space matrix that are regulated and calibrated with the crosscut regions indexes. Since, in this paper we study first,the adaptability of Transect method in typology of urban neighborhoods in 9th district of Mashhad. Then we study the compatibility of smart growth indexes with urban form characteristics of 9th district of Mashhad.

\section{Theoretical Foundations of Research}

Urban form can be defined as the spatial pattern of human activity at a specific period. Urban form is a terms using to describe physical elements in a city (Poormohammadi, Sadr Mousavi, \& Jamali, 1390). M.R.G. Canzan, is known as the head of urban morphology, considers four elements as components of urban shape: land usage, buildings structure, segmentation pattern and street pattern (Daneshpoor \& Moradi, 1391).

Rahnama takes into account four different aspects to determine the shape of the city including the city size, density, Gini index and Moran \& Geary index (Rahnama \& Abbas Zadeh, 1387).Many of the current social, economic, environmental and physical problems are directly consequences of producing urban spaces since World War II.Regarding the crises of climate change, energy dependency, public health, collapsing infrastructure and financial instability, we must keep in mind that all five categories are as the result of urban sprawl (Duani, Speck, \& Lydon, 2010).Late 20th century, inspired by the scientific foundations of sustainable development, a new approach called "New Urbanism" and "Smart Growth" apeared for stabilizing the space form of cities (Zarrabi, Saberi, \& Mohammadi, 1390).

In recent years, many communities have decided to build a model for the development of their communities based on principles and strategies of urban smart growth. These principles Encourages a mix of land uses, often reducing the need to travel, and Promotes a mix of housing types (Rahnama \& Abbas Zadeh, 1387). The crosscut defines a set of areas including the transmitting from scattered rural houses to urban dense core. Each region is divided into parts including the same transition from the edge to the neighborhood center.

Duany believes The Transect seeks to rectify the inappropriate intermixing of rural and urban elements known as sprawl. No desire for a particular type of development is categorically "wrong"; it is just in the wrong Transect location. The Transect eliminates the "urbanizing of the rural"-office towers in otherwise pristine 
environments-or, equally damaging, the "ruralizing of the urban"-undefined, vacant open space in the urban core. The prescribed urban pattern is therefore based on, theoretically, finding the proper balance between natural and human-made environments along the rural to urban Transect (Duany \& Talen, 2001).

Form-based regulation having six zones apart from the T1 as the most natural and rural index, up to T6 including the most urban and densest indexes of these regulation that describe the regulation, criteria and feature of each crosscut region entirety.

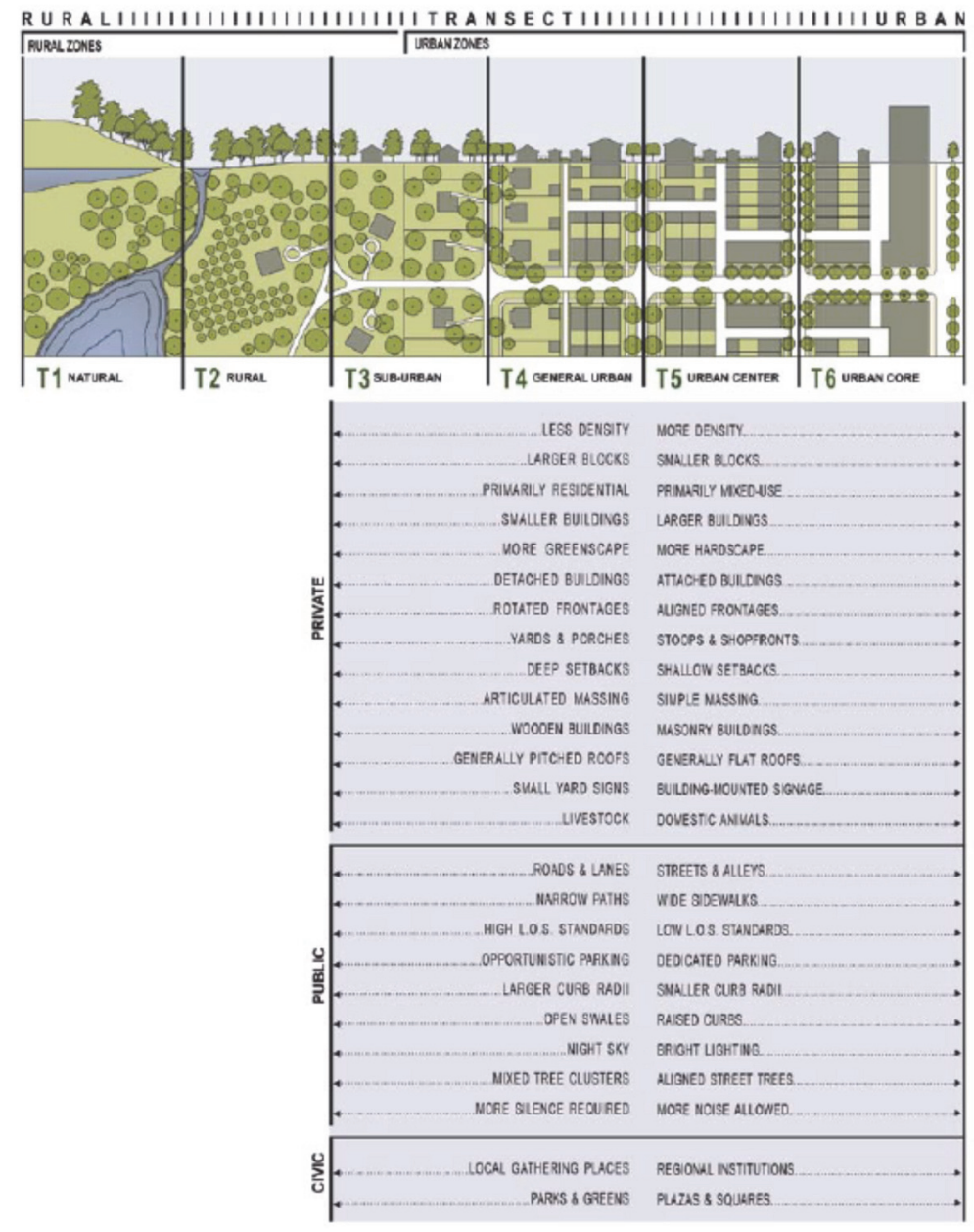

Figure 1. Transect ecozones in urban smart growth approach (Duany A., 2005)

This classification assures the designer that a proper form of construction has been established between buildings and streets. This approach also regulates the relationship between buildings, streets and pedestrians (Geller, 2010). In general, for Transect zoning approach up to now, two major methods are used:

The first method is the extension of the cross-sectional line in the city, which is usually used in urban regions with low complexity, and is like application of it in ecological sciences.

The second method is to use the principles and concepts of cross-sectional method for analyzing urban environments The cross-sectional method (crosscut) does not necessarily use a cross section, but based on the principles, concepts and methodology of crosscutting, the various dimensions of urban environments are zoned.

The above method is very efficient and effective for using in urban with diverse and complex conditions. In this type of application, various analytical methods, such as morphology, typology and typomorphology are used with shape and numerical approaches. Among the examples of these method is the zoning of Grass Valley City in California State (Mohammadi \& Mahabadi, 1393).

The rules and standards of smart growth, reduce separation of usages, but do not eliminate them. For example, the first zone of T1 is the most natural ones, including the city's reserve lands, and any construction in them is 
prohibited. The T1, T2 zones are biological reservoirs of urban spaces that necessarily located in vast lands around cities and natural landscapes in the cities; these are like heights, rivers, and ponds.

The $\mathrm{T} 3$ to $\mathrm{T} 5$ zones are residential zones that are extend from simple residential forms with a natural and rural form to urban densely populated environments with more general uses. For example, the T5 zone of the city center with a density of at least 15 and maximum 60 units per hectare (depending on the operation and urban preparing program) is determined; and the size of the urban blocks should be the pieces smaller than the previous zones (environment less than 610 square meters). The passages in these areas may include highways, main road, rural and standard roads. In addition, considering bicycle paths in these passages is necessary. The lot occupation consists maximum $80 \%$ of the land, which will be bigger than the previous zones and is smaller than the next zone. The number of floors should be between 3 to 5 floors, so that the urban landscapes look similar to the whole zone. (Duany A., 2005)

\section{Research Methodology and Statistical Sample Society}

The present research in terms of objective is applicable- development by using the quantitative-qualitative method. The nature and method of this research is analytical-descriptive; and is codified by the documentary studies of indexes and smart growth criteria. In this research, by analyzing theories and views, the urban form indexes with smart growth approach and form-based rules are analyzes and compared. The study area is southwest of Mashhad (zone No. 9 of the municipality).

According to the studies carried out with respect to natural landscapes, high-rise construction and physical diversity, geographic extent, population diversity and construction, and tendency towards development and renovation, southwest zone and 9th district of Mashhad municipality due to the adequacy of the indexes are selected for conducting field studies (Farnahad, 1384).

In the present research, as the criteria and characteristics of the urban form are valuable, the classification of transect district is important as well; because by determination of transect zones, the especial indexes of each zone can be obtained and compiled.

The first stage of the research is the determination of the transect zone of each area or urban block by using the space matrix and Space-Mate charts. For analyzing the indexes, the MCDM multi-criteria decision-making method was selected.

This method tracks a powerful and scientific process for categorizing, weighing, unscaling, and analyzing quantitative indexes (Mohammad Moradi \& Akhtar kavan, 2009). Therefore, based on the obtained matrix, we can judge and analyze the urban form on the scale of neighborhood units or urban blocks. This matrix of various urban aspects includes population density, environment, Thoroughfares, transportation, land-use, physical form, aesthetics, and configuration. It seems that the above matrix has been able to cover various aspects of urban form analysis based on the urban smart growth approach.

The statistical data in this research is the neighborhood units or pedestrian sheds, that have been used in urban development and new detailed plans of the Mashhad metropolis have used such scales under the title of urban area. The considered indexes in this study are often defined in the urban areas; that are transmitted directly to the adjusted tables and matrixes. (Rezvani Kakhki \& Rahnama, Comparison of Renovation of Damaged Fabrics with Smart Growth Approach (Case Study: Mashhad), 2016)

In the field of collecting data, firstly, appropriate information is gathered in relation to the variables of the research. Then the collected values are compared with the standards of the form-based codes. This comparison was performed using SPSS software and the hypothesis testing was done.

The present research area is 9th district of Mashhad Municipality. A part of that area is in form of crosscut in accordance with the transect method in smart growth from the beginning of Hashemieh Boulevard on the south side of Vakilabad Boulevard. It includes a direct route with about 5500 meters length and with 400-500 meters width toward the natural landscapes of Binalood Mountains called the Southern Heights. The mentioned line (trace) due to crossing has 160 meters height difference from beginning (Vaklabad Boulevard) to the end (southern heights and the eastern side of the Khorshid Park at the end of Hashemieh).

In the collection of information from urban maps, the 1/2000 scale of mapping organization (annexed) to the scald of 1/35000 using in detailed plans of the Mashhad Municipality are used; that in the studied area includes detailed specifications of all passages, plotting of zones, filled and empty spaces. In addition to the above maps, to update information, the field observations were used to modify the uses of indexes such as green spaces, business centers and public utilities, as well as access to residential areas including bus, taxi and bicycle stations. In the following, the gotten information from Mashhad Municipality includes new established statistics of 2015, 
library studies and online maps of Google Earth were used.

The studied urban areas in the present study are selected from the urban scale that are selected and planned by the design consultant's detailed development plan of 9th district of Mashhad Municipality. For example, the R143 area, located at the beginning of the eastern side of the Hashemieh Blvd, with dimensions of $450 \times 400$ square meters, with low residential density has been studied and regulated by the detailed plan. This area in the present research, after accurate and precision study, includes 12 urban blocks, which are totally divided into 209 lots mostly residential. The mentioned area due to having accesses to the main roads uses 3 bus stations, 1 taxi station and 1 bicycle station (Naghsh Piravosh, 1389).

The above indexes are replaced in the matrix (analytical-comparative) that are set forth in the theoretical part of research based on the most recent editing of the form-based codes in smart growth framework. As stated above, in general, multi-criteria models can be divided into two discrete and continuous groups in terms of the number of alternatives. Types of multi-criteria decision-making methods are as follows: weightless methods, weighing methods on criteria, and weighting methods on options (Mohammad Moradi \& Akhtar kavan, 2009).In weightless method, no any type of preference has specified by the decision maker; and only the decision matrix is expressed. In other word, the criteria and operation of each option on the criteria is specified. However, the decision maker expresses no any preference on criteria and/or alternative. In the process of multi criteria decision-making, each alternative is usually defined by two types attribute: qualitative and qualitative characteristics. Since converting qualitative characteristics to relative scale is difficult, most multi-index decision-making models use sequential scales and/or distances to convert qualitative features to a quantitative one (Mohammad Moradi \& Akhtar kavan, 2009). A general method for measuring a qualitative index with a distance scale is to use a bi-polar scale (Likert scale). This measure is based on a ten-point scale, so that zero specifies the minimum possible value and ten determines the maximum possible value of the considered index. This matrix has been set on transect zoning (cross section from urban indexes to natural indexes) and with 8 dimensions of smart growth criteria was analyzed with SPSS software comprehensively. Then, in a hypotheses test by one sample T test comparing average by using SPSS software is judged; so that during the research based on the obtained results, the scientific hypothesis to be judged.

\section{Research Findings}

The form-based codes that was compiled by André Duany executively, in newest version in 2005 was edited and stipulated the following indexes for settlements (Duany A., 2005).

The summary of the regulation and indexes of the previous part is shown in the below table; including the first table of classification of aspects and indexes in the form of qualitative criteria:

Table 1. The dimensions and indexes of urban form assessment matrix (research finding) (Duany A., 2005)

\begin{tabular}{|c|c|c|c|c|c|}
\hline & & & & & Criteria \\
\hline \multirow{4}{*}{ Public parking } & \multirow{4}{*}{ Taxi station } & TND Allocation & TOD Allocation & Residential-density & Density \\
\hline & & Green space & Planter & Lot occupation & Environment \\
\hline & & Bus station & BRT & Metro station & Transportation \\
\hline & & Grid density & Bicycle pad & Line width & Thoroughfares \\
\hline \multirow[t]{3}{*}{ Hospital } & Education & Retail & Civic & Mix use & Land-use \\
\hline & Block perimeter & Lot width & setback & Lot area & Physical-Form \\
\hline & & & $\begin{array}{l}\text { Street tree } \\
\text { Built density }\end{array}$ & $\begin{array}{l}\text { Streetlight } \\
\text { stories }\end{array}$ & $\begin{array}{l}\text { Aesthetic } \\
\text { Configuration }\end{array}$ \\
\hline
\end{tabular}

In this part, we examine the zoning of the urban form in 9th district; and compare the urban form indexes with the smart growth criteria and transect design.

This cut includes the most urban arena on Vakilabad Boulevard (M112) to the most natural arena (G322). Therefore, the proper diversity of the transect zones of the form-based code can be observed and analyzed in this section. 


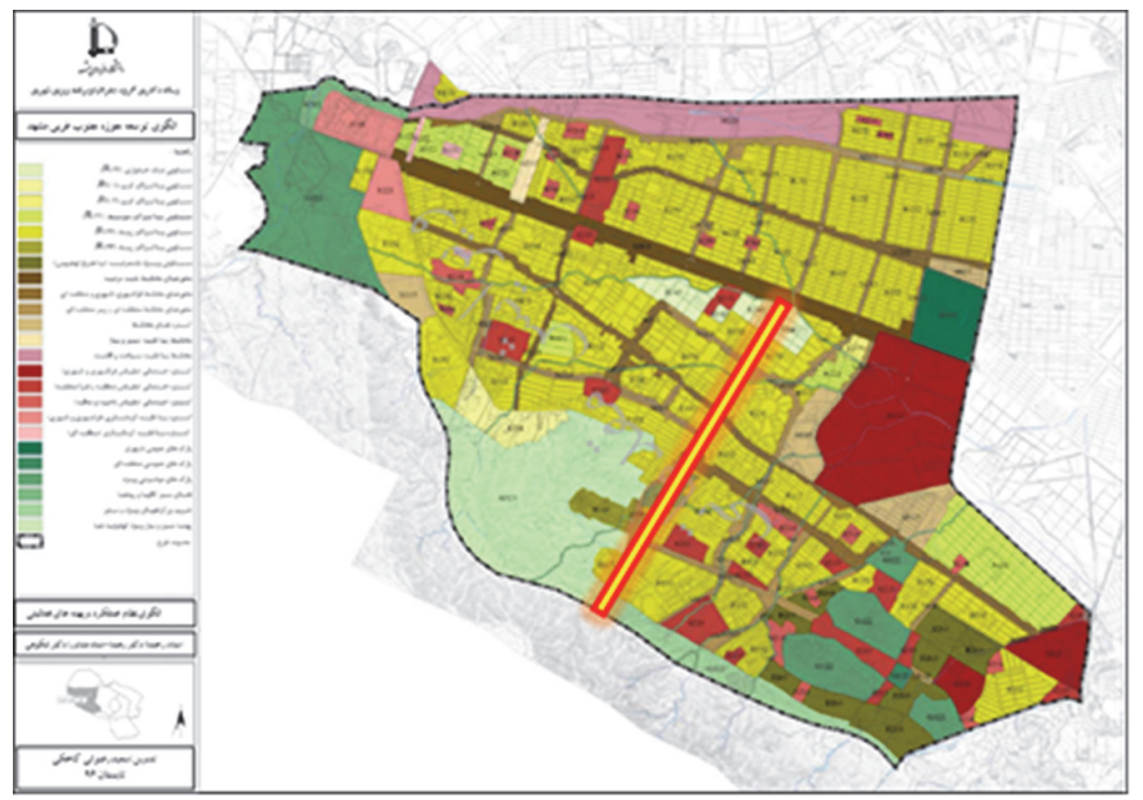

Figure 2. 9th district cross section (north south) of Mashhad (Naghsh Piravosh, 1389)

The units and designed areas in the cross-section have been taken from the development pattern of detailed plan of southwest area of Mashhad municipality; and their indexes have been summarized in a table.

Table 2. North-south cross section detailed map of 9th district of Mashhad (Naghsh Piravosh, 1389)

\begin{tabular}{llllllc}
\hline Unit area & $\boldsymbol{M 1 1 1}$ & $\boldsymbol{M 1 1 2}$ & $\boldsymbol{R 1 3 2}$ & $\boldsymbol{R 1 4 3}$ & $\boldsymbol{G 1 2 2}$ & $\boldsymbol{G 3 2 2}$ \\
\hline Land-use & $\begin{array}{c}\text { Residential tall } \\
\text { buildings }\end{array}$ & Mixe-use & residential-high & Residential-low & $\begin{array}{c}\text { Theme } \\
\text { Park }\end{array}$ & $\begin{array}{c}\text { Green } \\
\text { Landscape }\end{array}$ \\
Density & $500 \%$ & $300 \%$ & $240 \%$ & $100 \%$ & & \\
Floors.Nu & 13 & 8 & 5 & 2 & & \\
Lot area & 2000 & 1000 & 300 & 500 & & \\
Occupation & $80-25 \%$ & $80-40 \%$ & 50 & 50 & & \\
\hline
\end{tabular}

The first stage of the research is the determination of the transect zone for each urban area by using the space matrix diagrams. The Spacematrix method has contributed to a clarification in the terminology currently being used by urban planners working with urban density. Spacematrix defines density as a multi variable phenomenon and makes a correlation between density and the built mass (urban form). Spacematrix uses the following measures: floor space index (FSI), ground space index (GSI), and network density (N). These three measures are represented in a three-dimensional diagram, the Spacematrix. Measures such as open space radio (OSR) or spaciousness, the average number of floors or layers (L) and the size of the urban blocks (w) can be derived from that. For the purpose of this research Network density is not taken into consideration and we thus work with only one of the three planes in the Spacematrix diagram. Here FSI on the y-axis gives an indication of the built intensity in an area and the average number of floors (L) on the x-axis reflects the compactness of the development. The OSR and GSI are gradients that fan out over the diagram. OSR describes the spaciousness (or pressure on the non-built space) with blue lines, and GSI reflects the coverage(with pink lines).

In this chart, the defined area is specified for each transect zones. This classification is took place with a smart growth approach and transect method. Now, by finding the locus of each urban area having a clear and explicit definition, it can be located in one of transect limitations. In other words, it can be proceeded for measuring a specific form of the city. 


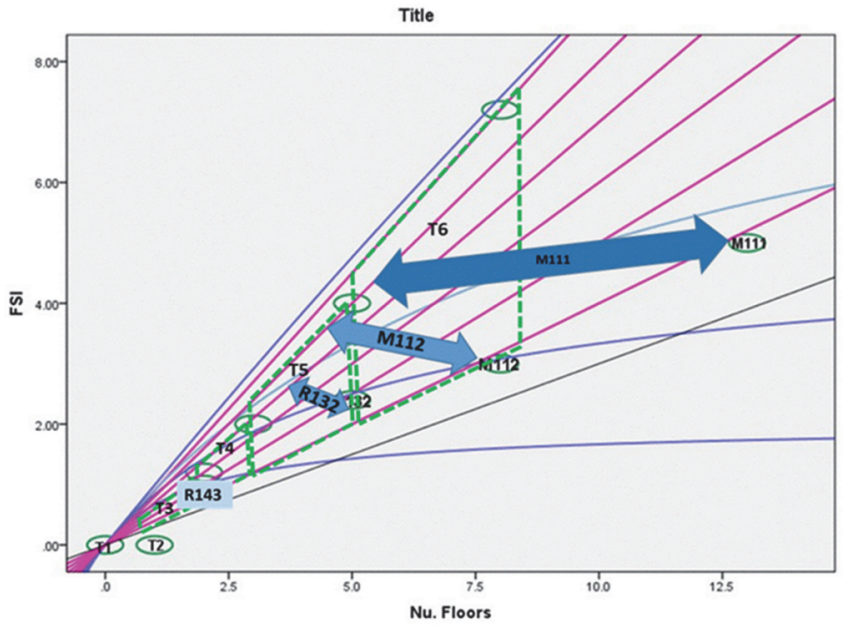

Diagram 1. The Compliance of neighborhood units in 9th district of Mashhad with the transect criteria with space matrix diagram (research finding)

By drawing the space matrix and placement of the designed areas of 9th district of Mashhad in the diagram, the following results are observed:

The area (M 111) is located in the special zone authorized for high-rise building that continuation of the defined criteria can be extended to the 6th T6 cross-section.

The area (M112) is located between the fifth and sixth (say T5 transect)

The area(R132) is located in the fifth $\mathrm{T} 5$ transect zone.

The area(R143) is located in the third $\mathrm{T} 3$ transect zone.

The area (G122) by considering the definition of park is a specific issue and due to allowed construction can be located in the $\mathrm{T} 2$ transect zone under the special criteria.

The area (G322) by considering the prohibition of construction and green zone of highway limitation can belong to the $\mathrm{T} 1$ transect zone.

The selected neighborhood units and areas in the 9th district, after determination of the transect zone, are studied in terms of the main indexes of urban smart growth and form-based codes.

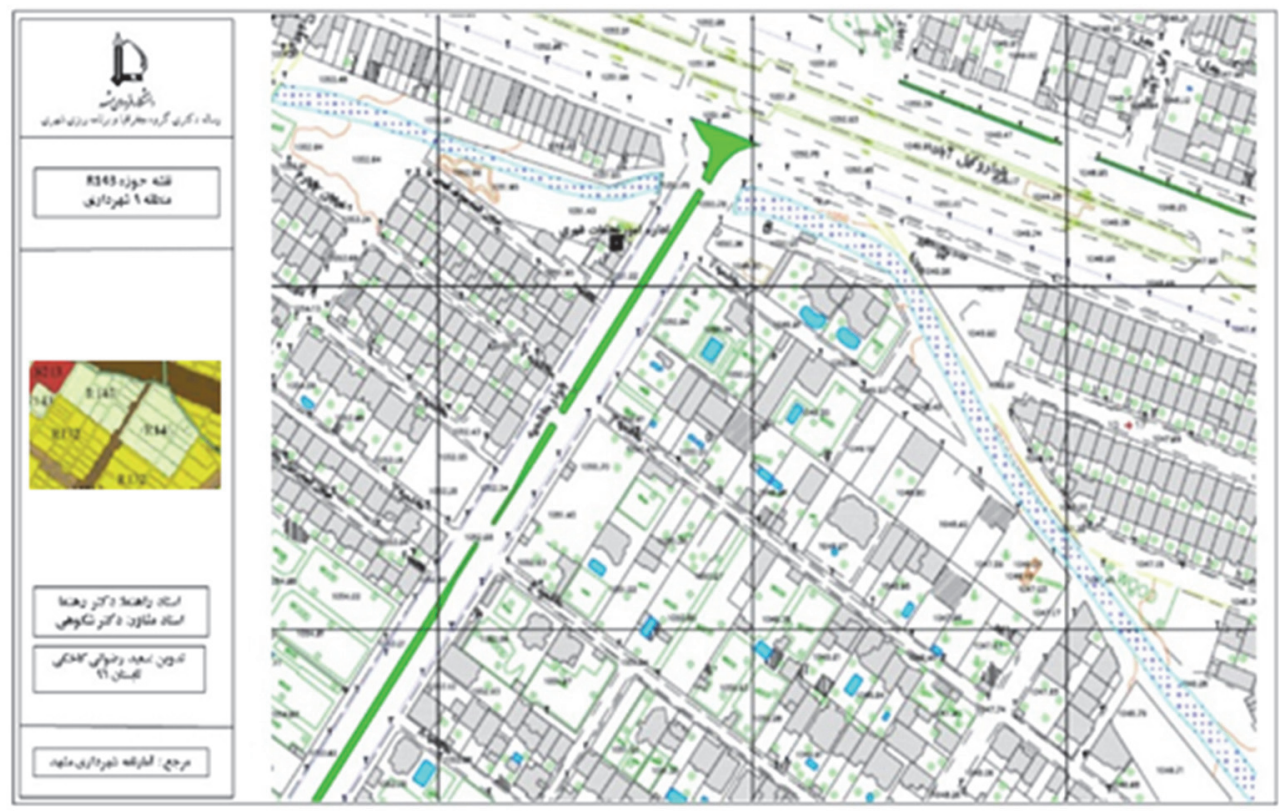

Figure 3. The map of R143 area of 9th district of Mashhad (Naghsh Piravosh, 1389) 
In the table 3, all 26 derived indexes from the urban form, which are categorized into 8 general groups, are collected and represented. This table shows the main criteria of scoring for the quality indexes of the urban form, which, according to the table descriptions, convert into quantitative and measurable indexes.

Table 3. The complete matrix of urban form assessment based on the crosscut zone (research finding)

\begin{tabular}{|c|c|c|c|c|c|c|c|}
\hline T6 & T5 & T4 & T3 & T2 & T1 & indexes & Criteria \\
\hline $\begin{array}{l}30- \\
\text { 240units/Hec }\end{array}$ & 15-60units/Hec & 10-30units/Hec & 5-15unit/Hec & 1unit/8 Hec & lunit/40 Hec & \begin{tabular}{|l|} 
Residential- \\
density
\end{tabular} & Density \\
\hline $70-100 \%$ & $0-30 \%$ & $0-30 \%$ & Prohibited & No minimum & No minimum & \begin{tabular}{|l} 
TOD \\
Allocation \\
\end{tabular} & \\
\hline Prohibited & $10-30 \%$ & $30-60 \%$ & $10-30 \%$ & No minimum & No minimum & \begin{tabular}{|l} 
TND \\
Allocation \\
\end{tabular} & \\
\hline $90 \%$ & $80 \%$ & $70 \%$ & $60 \%$ & By variance & By exception & Lot coverage & Environment \\
\hline $\begin{array}{l}\text { Tree- well-1.2- } \\
1.6 \mathrm{~m}\end{array}$ & \begin{tabular}{|l|} 
Regular- \\
planter-1.2- \\
$1.6 \mathrm{~m}$
\end{tabular} & \begin{tabular}{|l|} 
Regular- \\
planter-2.5- \\
$3.6 \mathrm{~m}$ \\
\end{tabular} & $\left|\begin{array}{l}\text { Regular- } \\
\text { planter-2.5-5m }\end{array}\right|$ & $\begin{array}{l}\text { Clasterd- } \\
\text { swale-2.5-5m }\end{array}$ & $\begin{array}{l}\text { Clasterd- } \\
\text { swale-2.5-5m }\end{array}$ & Planter & \\
\hline $\begin{array}{l}\text { Play.-Square- } \\
\text { Plaza }\end{array}$ & \begin{tabular}{|l|} 
Play.-Green- \\
Square-Plaza
\end{tabular} & \begin{tabular}{|l|} 
Playgroun- \\
Green-Square
\end{tabular} & $\begin{array}{l}\text { Playground- } \\
\text { Park-Green }\end{array}$ & $\begin{array}{l}\text { Playground- } \\
\text { Park }\end{array}$ & \begin{tabular}{|l} 
Playground- \\
Park
\end{tabular} & Green space & \\
\hline 3 in $500 \mathrm{~m}$ & 2 in $500 \mathrm{~m}$ & $1 \mathrm{in} 500 \mathrm{~m}$ & 1 in $500 \mathrm{~m}$ & No minimum & No minimum & Metro station & Transportation \\
\hline 3 in $500 \mathrm{~m}$ & 2 in $500 \mathrm{~m}$ & 1 in $500 \mathrm{~m}$ & 1 in $500 \mathrm{~m}$ & No minimum & No minimum & BRT & \\
\hline 3 in $500 \mathrm{~m}$ & 2 in $500 \mathrm{~m}$ & 1 in $500 \mathrm{~m}$ & 1 in $500 \mathrm{~m}$ & No minimum & No minimum & Bus station & \\
\hline 3 in $500 \mathrm{~m}$ & 2 in $500 \mathrm{~m}$ & 1 in $500 \mathrm{~m}$ & 1 in $500 \mathrm{~m}$ & No minimum & No minimum & Taxi station & \\
\hline 3 in $500 \mathrm{~m}$ & 2 in $500 \mathrm{~m}$ & 1 in $500 \mathrm{~m}$ & 1 in $500 \mathrm{~m}$ & No minimum & No minimum & Public parking & \\
\hline $3.0-3.6 \mathrm{~m}$ & $3.0-3.6 \mathrm{~m}$ & $2.7-3.0 \mathrm{~m}$ & $2.5-3.0 \mathrm{~m}$ & Permitted & Permitted & Line width & Thoroughfares \\
\hline mandatory & mandatory & mandatory & mandatory & mandatory & mandatory & Bicycle pad & \\
\hline 30 & 19 & 16 & 12 & No minimum & No minimum & Grid density & \\
\hline 4 & 4 & 3 & 2 & \begin{tabular}{|l|} 
Not \\
applicable
\end{tabular} & \begin{tabular}{|l|} 
Not \\
applicable \\
\end{tabular} & Mix use & Land-use \\
\hline $\begin{array}{l}\text { Retail-Gallery- } \\
\text { Restaurant }\end{array}$ & $\begin{array}{l}\text { Retail-Gallery- } \\
\text { Restaurant }\end{array}$ & $\begin{array}{l}\text { Retail-Gallery- } \\
\text { Restaurant }\end{array}$ & Open-market & Open-market & $\begin{array}{l}\text { Not } \\
\text { applicable }\end{array}$ & Retail & \\
\hline \begin{tabular}{|l|} 
Fire-Police- \\
Clinic \\
\end{tabular} & \begin{tabular}{|l|} 
Fire-Police- \\
Clinic \\
\end{tabular} & Fire-Police & Fire & \begin{tabular}{|l|} 
Not \\
applicable
\end{tabular} & \begin{tabular}{|l|} 
Not \\
applicable
\end{tabular} & Civic & \\
\hline \begin{tabular}{|l|} 
Childcare- \\
Elementary \\
\end{tabular} & \begin{tabular}{|l|} 
Childcare- \\
Elementary
\end{tabular} & \begin{tabular}{|l|} 
Childcare- \\
Elementary
\end{tabular} & Childcare & Childcare & \begin{tabular}{|l|} 
Not \\
applicable
\end{tabular} & Education & \\
\hline No minimum & $140 \mathrm{~m} 2$ & $230 \mathrm{~m} 2$ & $460 \mathrm{~m} 2$ & \begin{tabular}{|l|} 
Not \\
applicable \\
\end{tabular} & \begin{tabular}{|l|} 
Not \\
applicable
\end{tabular} & Lot area & Physical-Form \\
\hline $2 \mathrm{~m}-3.5 \mathrm{~m}$ & $2 \mathrm{~m}-3.5 \mathrm{~m}$ & $5.5 \mathrm{~m}-7.5 \mathrm{~m}$ & $10 \mathrm{~m}$-more & No minimum & No minimum & setback & \\
\hline $5.5 \mathrm{~m}$ & $5.5 \mathrm{~m}$ & $9 \mathrm{~m}$ & $15 \mathrm{~m}$ & \begin{tabular}{|l|} 
Not \\
applicable
\end{tabular} & \begin{tabular}{|l|} 
Not \\
applicable
\end{tabular} & Lot width & \\
\hline $600 \mathrm{~m}$ & $600 \mathrm{~m}$ & $730 \mathrm{~m}$ & $910 \mathrm{~m}$ & \begin{tabular}{|l|} 
Not \\
applicable
\end{tabular} & \begin{tabular}{|l|} 
Not \\
applicable
\end{tabular} & \begin{tabular}{|l|} 
Block \\
perimeter
\end{tabular} & \\
\hline Column-double & Column-double & Post-Column & Pipe-Post & Pipe-Post & Cobra Head & Streetlight & Aesthetic \\
\hline Palm-Oval-Ball & Palm-Oval-Ball & \begin{tabular}{|l} 
Palm-Oval-Ball- \\
Vase....
\end{tabular} & $\begin{array}{l}\text { Palm-Oval- } \\
\text { Ball-Vase.... } \\
\end{array}$ & \begin{tabular}{|l|} 
Palm-Oval- \\
Ball-Vase.... \\
\end{tabular} & \begin{tabular}{|l|} 
Palm-Oval- \\
Ball-Vase.... \\
\end{tabular} & Street tree & \\
\hline $2-6 \mathrm{st}$ & $2-4 \mathrm{st}$ & $1-3 \mathrm{St}$ & $1-2 \mathrm{St}$ & \begin{tabular}{|l|} 
Not \\
applicable \\
\end{tabular} & \begin{tabular}{|l|} 
Not \\
applicable \\
\end{tabular} & stories & Configuration \\
\hline $540 \%$ & $320 \%$ & $210 \%$ & $120 \%$ & $\begin{array}{l}\text { Not } \\
\text { applicable }\end{array}$ & $\begin{array}{l}\text { Not } \\
\text { applicable }\end{array}$ & Built density & \\
\hline
\end{tabular}

In the following pages, the studied areas in 9th district of Mashhad municipality are analyzed according to the above table. These areas are first classified in the previous section according to the space matrix method and transect zone; then they compare with the indexes of the specified transect zone. The following tables, respectively, examine matrixes of urban form in the areas including M111, M112, G122, and G322; in which quantitative indexes are used to measure the compatibility with smart growth. The main criterion of all indexes is presented from the form-based regulation of urban smart growth and by determination of transect zone by the space matrix diagrams. 
Table 4. The urban form indexes in R143 area (spss of research findings)

\begin{tabular}{|c|c|c|c|c|c|c|c|c|c|c|}
\hline R143 & score 10 & score 8 & score 6 & score 4 & score 2 & score 0 & R143 & T3 & indexes & Criteria \\
\hline 2 & $<15$ & $15-18$ & $18-21$ & $21-24$ & $24-27$ & $27-30$ & 27 & 5-15unit/Hec & $\begin{array}{l}\text { Residential- } \\
\text { density } \\
\end{array}$ & Density \\
\hline 2 & $15-30 \%$ & 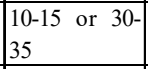 & 10 or $35-40$ & $5-10$ or $40-45$ & $0-5$ or $45-50$ & $0-5$ or $50-55$ & $>50 \%$ & $10-30 \%$ & \begin{tabular}{|l|} 
TND \\
Allocation \\
\end{tabular} & \\
\hline 10 & Prohibited & $10 \%$ & $15 \%$ & $20 \%$ & $25 \%$ & $30 \%$ & Prohibited & Prohibited & \begin{tabular}{|l|} 
TOD \\
Allocation \\
\end{tabular} & \\
\hline 4 & $4 m-5 m$ & $3 m-4 m$ & $2 m-3 m$ & $1 \mathrm{~m}-2 \mathrm{~m}$ & $0-1 \mathrm{~m}$ & 0 & $1-1.5 \mathrm{~m}$ & \begin{tabular}{|l|} 
Regular- \\
planter-2.5-5m
\end{tabular} & Planter & Environment \\
\hline 8 & park & Green & Square & Green-belt & playground & No park & Green-Park & \begin{tabular}{|l} 
Playground- \\
Park-Green
\end{tabular} & Green space & \\
\hline 2 & 60 & 58 & 55 & 53 & 50 & $<50$ & $50 \%$ & $60 \%$ & Lot coverage & \\
\hline 2 & $>4$ & 4 & 3 & 2 & 1 & 0 & 1 & 1 in $500 \mathrm{~m}$ & Metro station & Transportation \\
\hline 0 & $>4$ & 4 & 3 & 2 & 1 & 0 & 0 & 1 in $500 \mathrm{~m}$ & BRT & \\
\hline 6 & $>4$ & 4 & 3 & 2 & 1 & 0 & 3 & 1 in $500 \mathrm{~m}$ & Bus station & \\
\hline 2 & $>4$ & 4 & 3 & 2 & 1 & 0 & 1 & 1 in $500 \mathrm{~m}$ & Taxi station & \\
\hline 2 & $>4$ & 4 & 3 & 2 & 1 & 0 & 1 & 1 in $500 \mathrm{~m}$ & Public parking & \\
\hline 10 & $2.5-3 \mathrm{~m}$ & $2-2.5 \mathrm{~m}$ & $1.8-2.0 \mathrm{~m}$ & $1.5-1.8 \mathrm{~m}$ & $1.2-1.5 \mathrm{~m}$ & $<1.5 \mathrm{~m}$ & 3 & $2.5-3.0 \mathrm{~m}$ & Line width & Thoroughfares \\
\hline 10 & 1 & & & & & 0 & 1 & mandatory & Bicycle pad & \\
\hline 2 & 12 mile/mile2 & 15 mile/mile2 & 20mile/mile2 & 25mile/mile2 & 30mile/mile2 & $>30$ mile/mile2 & 30 & 12 & Grid density & \\
\hline 10 & 4 & 3 & & 2 & 1 & 0 & 4 & 2 & Mix use & Land-use \\
\hline 10 & 1 & & & & & 0 & 1 & Open-market & Retail & \\
\hline 10 & 1 & & & & & 0 & 1 & Childcare & Education & \\
\hline 10 & 1 & & & & & 0 & 1 & Fire & Civic & \\
\hline 10 & $450-500 \mathrm{~m} 2$ & $400-450 \mathrm{~m} 2$ & $350-400 \mathrm{~m} 2$ & $300-350 \mathrm{~m} 2$ & $250-300 \mathrm{~m} 2$ & $<250 \mathrm{~m} 2$ & 500 & $460 \mathrm{~m} 2$ & Lot area & Physical-Form \\
\hline 2 & $>10 \mathrm{~m}$ & $8-10 \mathrm{~m}$ & $6-8 \mathrm{~m}$ & $4-6 \mathrm{~m}$ & $2-4 \mathrm{~m}$ & $0-2$ & 3-25 m & $10 \mathrm{~m}$-more & setback & \\
\hline 2 & $13-15 \mathrm{~m}$ & $11-13 \mathrm{~m}$ & 9-11 m & $7-9 \mathrm{~m}$ & $5-7 \mathrm{~m}$ & $<5 \mathrm{~m}$ & 6 & $15 \mathrm{~m}$ & Lot width & \\
\hline 10 & $<912$ & $900-1000 \mathrm{~m}$ & $1000-1100 \mathrm{~m}$ & $1100-1200 \mathrm{~m}$ & $1200-1300 \mathrm{~m}$ & $>1300 \mathrm{~m}$ & 612 & $910 \mathrm{~m}$ & \begin{tabular}{|l|}
$\begin{array}{l}\text { Block } \\
\text { perimeter }\end{array}$ \\
\end{tabular} & \\
\hline 6 & Pipe-Post & & standard light & & light & No light & Cobra Head & Pipe-Post & Streetlight & Aesthetic \\
\hline 10 & standard & & & & Minimum & No tree & palm-ball & \begin{tabular}{|l|} 
Palm-Oval-Ball- \\
Vase.... \\
\end{tabular} & Street tree & \\
\hline 10 & $\max -2$ & & & & & & $\max 2$ & $1-2 \mathrm{St}$ & stories & Configuration \\
\hline 10 & $100 \%$ & $120 \%$ & $140 \%$ & $160 \%$ & $180 \%$ & $>18-\%$ & $100 \%$ & $120 \%$ & Built density & \\
\hline $6 / 230$ & & & & & & & & & & \\
\hline
\end{tabular}

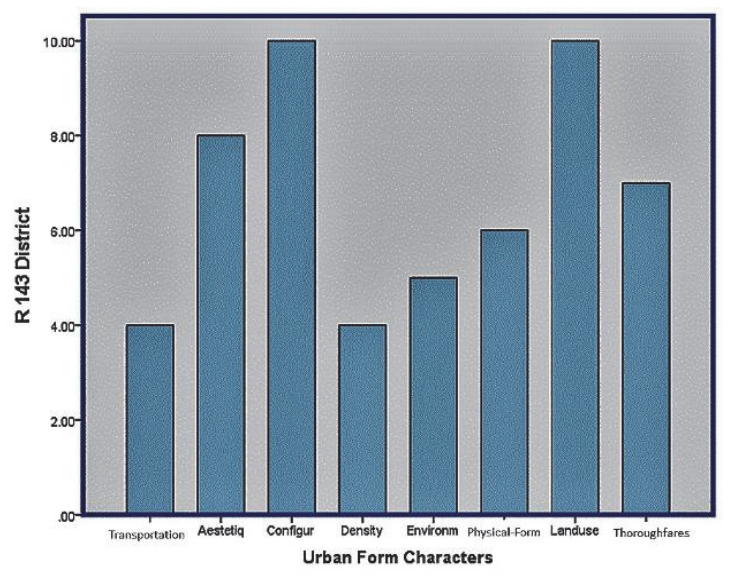

Diagram 2. Comparison of the urban form indexes in the studied zones R143 (spss, research findings)

Table4, include multi-criteria decision-making datas, examining the 26 indexes of smart growth in classification of various aspects. The inserted scores in the end column represent the degree of compliance and compatibility of these indexes with the urban smart growth regulations. The above scores are without weight and scale and are 
set from zero to ten. In each row, in addition to the score of each index by facilities of statistical software, a portion of the related row corresponding to the number of points is colored. At the end of the column, the scores total average of each column is calculated and inserted. According to the gathered scores and averages, the first overall result is that the average score of the indexes is always more than $50 \%$, which seems to be consistent with the urban smart growth regulations.

The obtained result from the comparison shows that in the above aspects and headings, configuration and Land-use indexes have the most similarity with the smart growth framework. It seems that the focus of comprehensive and detailed plans on zoning is the reason of this similarity. In addition,transportation and density indexes have the least similarities.

In the below diagram (No. 3), at the same time, all urban areas were investigated and the overall status of each six zones has been shown in a diagram. The highest conformity in the mixed zone was seen in M111 and the least conformity in residential zone was observed in R132.

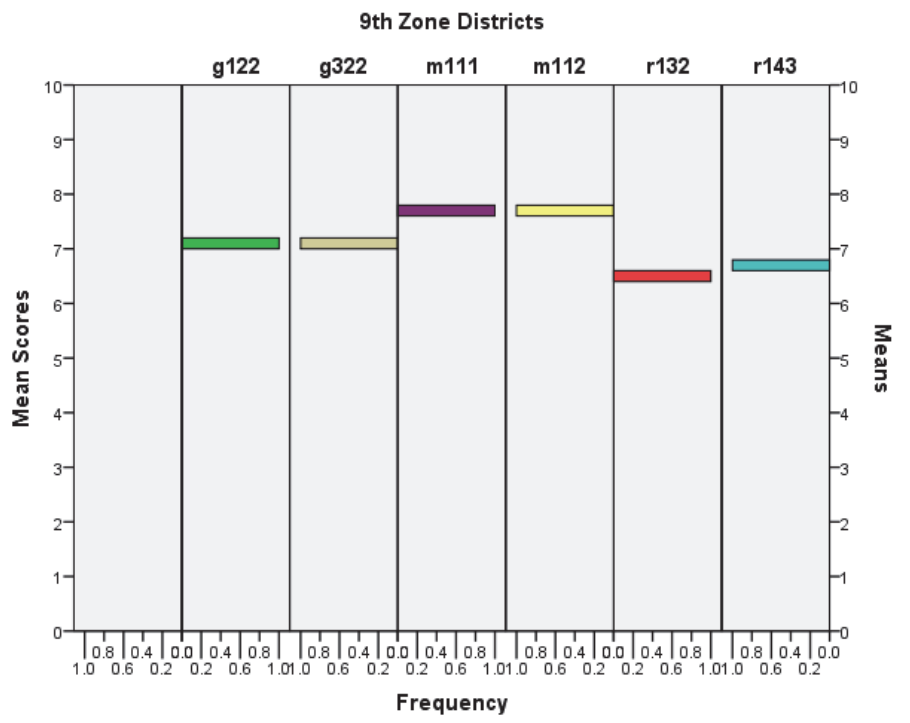

Diagram 3. Comparison of the urban form indexes in the studied zones in 9th district of Mashhad (spss, research findings)

To obtain a precise result, the statistical methods of the hypothesis test are used.

\section{Hypotheses Test}

The One-Sample T.test is a table that based on its contents it is possible to judge about acceptance or rejection of research. The $\mathrm{H} 1$ hypothesis is defined as follow:

H1:) Mean $>=50$ if the average scores of smart growth in the studied zone is equal or more than 50 .

$\mathrm{H} 0$ hypothesis is according to an average of smart growth scores less than $50 \%$, which suggests the lack of observation of urban smart growth approach in the design of the considered area.

In the SPSS software, one of the solutions is to use a confidence interval for the difference in means. If the upper and lower limits of the confidence interval are positive, with clear probability ( $95 \%$ here) the difference mean will be a value greater than zero and positive. As a result, it can be included that the average will be over 50\%; and if both upper and lower limits are negative, it means that with clear probability, the mean will be less than $50 \%$.

R143 area: In this area, the indexes in the SPSS software are analyzed and after setting the confidence interval on $95 \%$ the following result is obtained: 
Table 5. One sample test result for R143 urban area in 9th district of Mashhad (spss research finding)

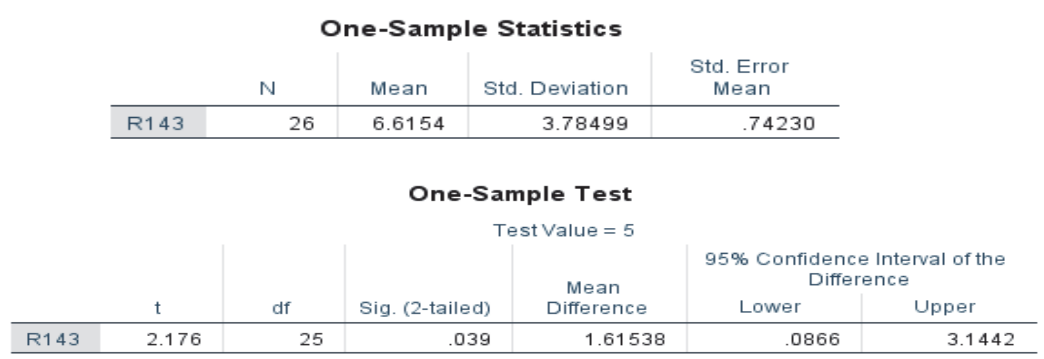

The above statistical results with the probability of $95 \%$ have the considered confidence for being the numerical mean of the indexes above $50 \%$ in comparison with the form-based codes of urban smart growth. Therefore:

With a $95 \%$ probability, the numerical average of residential area R143 index with smart growth indexes has a compatibility higher than $50 \%$.

By examining the assumptions of other urban areas, the following results are obtained:

With a $90 \%$ probability, the numerical average of residential area R132 index with smart growth indexes has a compatibility higher than $50 \%$.

With a 95\% probability, the numerical average of mixed corridor M111 index with smart growth indexes has a compatibility higher than $60 \%$.

With a $95 \%$ probability, the numerical average of mixed corridor M112 index with smart growth indexes has a compatibility higher than $60 \%$.

With a 95\% probability, the numerical average of Green area G322 index with smart growth indexes has a compatibility higher than $50 \%$.

With a $95 \%$ probability, the numerical average of Green area G122 index with smart growth indexes has a compatibility higher than $60 \%$.

\section{Conclusion}

In this chapter in $9^{\text {th }}$ district of Mashhad, firstly, for beginning the urban form studies, a suitable cross-section was drawn up including the most options of urban dense areas and marginal natural ranges. After selecting a northsouth cross-section in the considered area and extracting the urban form indexes, the obtained result is that the areas in the cross-section line of the $9^{\text {th }}$ district located in the boundaries of the T1, T2, T3, T5, and T6 transect zones are suitable for establishing. These transect zones were located and determined based on space matrix diagrams. Thus the transect method can be applied in $9^{\text {th }}$ district of Mashhad. The next step is to determine the main and detailed indexes of smart growth in each of the transect zones. In the urban smart growth approach, first, according to the transect classification, it was proceeded to determine the overall urban type from the first to sixth zone, then in each transect zone, the specific indexes of the zone are designated. Therefore, at this stage, the main indexes of the urban form referring to each transect zone were extracted. In this part of the research, the new edition of form-based codes (6.5) was used. The inferred indexes were assessed by multi-criteria decision-making method, and the desired result is obtained. The obtained matrix includes 26 different urban form indexes. The final step of the research is to conduct the field study on the urban smart growth in order to compare the collected indexes with the standards of the form-based codes in smart growth.

In this chapter, the designed areas and zones in the urban development patterns of $9^{\text {th }}$ district of Mashhad City were inserted in the above matrixes.

The above tables include multi-criteria decision-making matrixes that examine 26 matrixes of urban form in the category of variety of aspects. The inserted scores in the end column represent the degree of compliance and compatibility of these indexes with the urban smart growth regulations. The above scores are without weight and scale and are set from zero to ten. In these scores, the zero indicates the full incompatibility and the number 10 represents full compatibility. Therefore, based on the average and middle statistical properties in the statistical tables, score fice, which represents $50 \%$ conformity with smart growth criteria, is considered as the boundary between smart urban growth and sprawl.

In each row, in addition to the score of each index, by using the statistical software facilities a part of the row 
corresponding to the number of score is colored. At the end of the column, the average of the total scores of the column is calculated and inserted (Table 3).

According to the scores and averages, the first overall result is that the total average of indexes scores is always more than $50 \%$, which seems to be in the boundary of compliance with the urban smart growth regulations.

In this part, the eight aspects of urban form indexes were analyzed in the form of statistical diagrams to provide an introduction for determining the weaknesses and strengths of urban regulations and plans.

Regarding hypothesis test, according to the compliance of more than $50 \%$ of the 26 indexes of urban areas and neighborhoods of the development pattern of No.9 district, generally it seems that the orientation of the new urban regulation and patterns is toward avoiding from dispersion and tending to the ecologic approaches and compaction in the smart growth concepts.

\section{References}

Berghauser, P. M., \& Haupt, P. (2009). Space, Density and Urban Form. Netherlands.

Berghauser, P. M., Nes, A. V., \& Mashhoodi, B. (2012). Combination of Space Syntax with Spacematrix and the Mixed Use Index. Eighth International Space Syntax Symposium. Santiago de Chile. PAPER REF \# 8003

Daneshpoor, A., \& Moradi, S. (2012). Explaining methods of Form-typology \& their application in urban desighn. Architectural \& Urbanism Letter, 9, 65-78. october15, 1391.

Duani, A., Speck, J., \& Lydon, M. (2010). The Smart Growth Manual. McGraw Hill. https://doi.org/10.4067/S0718-34022012000100010

Duany, A. (2005). SmartCode 6.5. Retrieved from http://www.dpz.com

Duany, A., \& Talen, E. (2001). Making the good easy: the smart code alternative. Fordham Urban Law Journal, 29(4), 1445-1464.

Farnahad, E. C. (2005). Developement \& construction plan of Mashhad region. Mashhad: Road \& Urbanism ministry.

Geller, S. R. (2010, Fall). The Legality of Form-Based Zoning Codes. Journal of Land Use, 26, 44. https://10.1080/13574809.2013.772883

Mahdizadeh, J. (2003). Urban Strategic developement planning(Iran today practices). Tehran: Road @ urbanism ministry.

Mohammad, M. A., \& Akhtar, K. M. (2009). Methodology of multi-criteria decision making models. Armanshahr, 113.

Mohammadi, M., \& Mahabadi, Z. (2014). Urban texture zonning by transect method (1th district in esfahan). Iranian Restoration \& Architecture Scientific Research Periodical, 75-96.

Naghsh, P. C. E. (2010). Developement pattern \& Detailed plan of west-south of Mashhad. mashhad: Planning \& Developement organization of Mashhad.

Poormohammadi, M., Sadr, M. M., \& Jamali, S. (2011, Automn). Vakavi Maktabhaye morphology shahri. Geographic Studies of Dry Areas, 5(2), 1-16. Retrieved, 8,18, 1390.

Rahnama, M., \& Abbas, Z. G. (2008). Urbna physical-form measure. Mashhad: Jahad daneshgahi Mashhad.

Rezvani, K. S., \& Ajza, S. M. (2017). Investigating the Transit Oriented Development in New Urbanism, Case Study: Subway Stations Development in Mashhad. Modern Applied Science, 159-168. https://10.5539/mas.v11n1p159

Rezvani, K. S., \& Rahnama, M. R. (2016). Comparison of Renovation of Damaged Fabrics with Smart Growth Approach (Case Study: Mashhad). Modern Applied Science, 106-118. https://10.5539/mas.v10n10p106

Zarrabi, A., Saberi, H., \& Mohammadi, J. (2011). Spatial analysis of smart growth indexes in esfahan city. Human Geography Researches, 1-17.

\section{Copyrights}

Copyright for this article is retained by the author(s), with first publication rights granted to the journal.

This is an open-access article distributed under the terms and conditions of the Creative Commons Attribution license (http://creativecommons.org/licenses/by/4.0/). 